Pesq. Vet. Bras. 36(6):473-478, junho 2016 DOI: $10.1590 / \mathrm{S} 0100-736 \mathrm{X} 2016000600003$

\title{
Estudo comparativo e validação de três técnicas de PCR em tempo real (qPCR) para diagnóstico de Peste Suína Africana ${ }^{1}$
}

\author{
Eduardo L. Ribeiro ${ }^{2}$, Anna G.G. Oliveira ${ }^{2}$, Mateus Laguardia-Nascimento ${ }^{2}$, Camila Pacheco \\ Silveira Martins da Mata $^{3}$, Jenner K.P. dos Reis ${ }^{3 *}$ e Antônio A. Fonseca Júnior ${ }^{2}$
}

\begin{abstract}
Ribeiro E.L., Oliveira A.G.G., Laguardia-Nascimento M., Mata C.P.S.M.N., Reis J.K.P. \& Fonseca Jr A.A. 2016. [Comparative study and validation of three quantitative PCR (qPCR) techniques for the diagnosis of African Swine Fever.] Estudo comparativo e validação de três técnicas de PCR quantitativa (qPCR) para diagnóstico de Peste Suína Africana. Pesquisa Veterinária Brasileira 36(6):473-478. Departamento de Medicina Veterinária Preventiva, Escola de Veterinária, Universidade Federal de Minas Gerais, Av. Pres. Antônio Carlos 6627, Pampulha, Belo Horizonte, MG 31270-901, Brazil. E-mail: jenner@ufmg.br

This study evaluated the performance of three real time PCR techniques (qPCR) for the diagnosis of African Swine Fever in tissue samples. The three chosen techniques are based on amplification of viral protein VP72 gene sequences and are recommended by OIE (PSA-OIE), the United States official laboratories (PSA-USDA) and the European Union (PSA-EU). Target sequences of the viral DNA were inserted into synthetic plasmid, which served as a positive control for the standardization of techniques and optimization of reagents, determination of limits of detection and performance verification testing. To gauge repeatability and reproducibility of techniques, standard procedures were repeated on different days by two analysts and by changing mix reagents and equipment, and also by another laboratory. Analytical sensitivity tests were done with reference samples provided by an OIE reference laboratory and analytical and diagnostic specificity were tested with negative samples. The PSA-EU and PSA-USDA techniques were more advantageous to use because of lower concentration of oligos used. There were no significant differences in quantitative results varying the days of tests, analysts, equipment and the mix of reagents. The three techniques had high analytical and diagnostic specificity and sensitivity. The three qPCR techniques were considered equivalent and effective and can be adopted by any laboratory for issuing official diagnosis of African Swine Fever.
\end{abstract}

INDEX TERMS: PCR Real-Time, African swine fever virus, validation.

RESUMO.- Este estudo verificou o desempenho de três técnicas de PCR quantitativa (Real-Time) para o diagnóstico de Peste Suína Africana, uma doença exótica no Brasil, a partir de amostras de tecidos. As três técnicas escolhidas baseiam-se na amplificação de sequências do gene da proteína viral VP72 e são preconizadas, cada uma, por laboratórios oficiais da OIE (PSA-OIE), dos Estados Unidos (PSA-

\footnotetext{
${ }^{1}$ Recebido em 30 de dezembro de 2015.

Aceito para publicação em 31 de março de 2016.

${ }^{2}$ Laboratório de Biologia Molecular, Laboratório Nacional Agropecuário (Lnagro), Ministério da Agricultura, Pecuária e Abastecimento (MAPA), Rua Rômulo Joviano, s/n, Pedro Leopoldo, MG 33600-000, Brasil.

${ }^{3}$ Departamento de Medicina Veterinária Preventiva, Escola de Veterinária, Universidade Federal de Minas Gerais (UFMG), Av. Pres. Antônio Carlos 6627, Pampulha, Belo Horizonte, MG 31270-901, Brasil. *Autor para correspondência: jenner@ufmg.br
}

-USDA) e da União Europeia (PSA-EU), respectivamente. Oligonucleotídeos iniciadores e sondas de hidrólise marcadas com fluoróforos foram sintetizados conforme a literatura de referência consultada. Sequências-alvo do DNA viral foram inseridos em plasmídeo sintético, os quais serviram de controle positivo para a padronização das técnicas e otimização de reagentes, determinação dos limites de detecção e testes de verificação de desempenho. Para aferição de repetibilidade e reprodutibilidade das técnicas, as técnicas padronizadas foram repetidas em dias diferentes, por um segundo analista, com alteração no mix comercial de reagentes utilizado e em um equipamento diferente, e também por outro laboratório. Realizaram-se, ainda, provas de sensibilidade analítica com amostras de DNA viral de referência e especificidade analítica e diagnóstica, com amostras negativas. As técnicas de PSA-EU e PSA-USDA 
apresentaram-se mais vantajosas quanto ao consumo de iniciadores. Não houve diferenças significativas nos resultados quantitativos variando-se os dias dos ensaios, os analistas, os equipamentos e o mix de reagentes. As três técnicas apresentaram alta especificidade analítica e diagnóstica e sensibilidade diagnóstica. As três técnicas de qPCR mostraram-se eficazes para serem adotadas por um mesmo laboratório para emissão de diagnósticos oficiais de Peste Suína Africana.

TERMOS DE INDEXAÇÃO: PCR Real-Time, Peste Suína Africana, validação.

\section{INTRODUÇÃO}

A Peste Suína Africana (PSA) é uma doença viral que afeta suínos domésticos, com morbidade e mortalidade altas e causadora de expressivas perdas econômicas. É uma doença de notificação obrigatória (lista A) segundo a Organização Mundial de Saúde Animal (OIE 2012). 0 vírus causador é classificado como membro do gênero Asfivirus, família Asfaviridae. É o único arbovírus de DNA conhecido e seu genoma é de fita dupla (Dixon et al. 2000, Gallardo et al. 2014). É capaz de infectar suídeos (porco doméstico e selvagem, javali, porco-do-mato, porco gigante da floresta) e carrapatos argasídeos do gênero Ornithodoros. Em regiões endêmicas, como a África subsaariana, onde há presença do vírus e do vetor, a transmissão pela picada do carrapato é a principal rota de infecção (Done et al. 2001). No entanto, surtos em outras regiões do mundo já foram identificados, como Sul da Europa e América Latina, associados com importação de alimentos contaminados, nas décadas de 70 e 80 (Wilkinson 1989). Fezes e sangue são os principais contaminantes ambientais, devido à persistência do vírus por mais tempo (Done et al. 2001).

Os sinais clínicos da PSA são considerados indistinguíveis dos achados em casos de infecção pelo pestivírus da Peste Suína Clássica (PSC), outra doença de notificação obrigatória e causadora de grande morbidade e perdas econômicas. Observam-se febre alta, diarreia, hemorragias e presença de vermelhidão generalizada da pele. Esplenomegalia e hemorragias em linfonodos e rins são os achados de necropsia mais comuns (Done et al. 2001). Entretanto, a alta letalidade, hemorragias efusivas, acentuada esplenomegalia e linfonodos repletos de sangue com aspecto de hematomas distingue a PSA da PSC, o que permitiu fazer o diagnóstico presuntivo no surto de PSA em 1978, em Paracambi/RJ, e a tomada imediata de medidas para extinção do foco (Tokarnia et al. 2004). 0 diagnóstico diferencial de PSA pode ser feito também com síndrome nefropática e dermatite porcina (PNDS), síndrome respiratória e reprodutiva dos suínos (PRSS), salmonelose septicêmica, erisipela, pseudorraiva, estreptococose, pasteurelose, carbúnculo hemático e infecções que causam septicemia. (Radostits et al. 2007, Moura 2010).

A detecção rápida e precisa do vírus da PSA é fundamental para a contenção da doença, sobretudo em casos de surtos onde o vírus é exótico e também para avaliação pré-clínica da doença. Diagnóstico laboratorial preconizado inclui o isolamento viral na medula óssea, imunofluorescên- cia, ELISA e detecção do DNA viral por Reação em Cadeia da Polimerase (PCR). Este último tem ganhado relevância como um método rápido e alternativo ao isolamento viral, além de permitir a detecção do vírus mesmo em amostras biológicas de qualidade inferior ou degradadas (OIE 2012, De León et al. 2013, Penrith et al. 2013).

As técnicas de PCR quantitativa (qPCR ou em Tempo Real) tem sido desenvolvidas a partir do uso de sondas de hidrólise fluorogênicas (Taqman ${ }^{\circledR}$ ). A OIE adota em seus manuais a preconizada por King et al. (2003), cuja técnica foi padronizada com base em sequências do gene da proteína VP72, do capsídeo viral, observadas em diversas amostras virais, de várias partes do mundo e de diferentes grupos genotípicos. Zsak et al. (2005) também adotaram a proteína VP72 como alvo, desenvolvendo iniciadores próprios, e testando a viabilidade da técnica em avaliações pré-clínica, poucos dias após a infecção experimental em suínos. Tal técnica é indicada pelo Departamento de Agricultura dos Estados Unidos (USDA), com vistas ao estabelecimento de diagnósticos rápidos e precisos, em situações adversas e em grandes planteis, mesmo antes de manifestações clínicas da doença. As abordagens diagnósticas sobre a detecção dos genes da proteína VP72 foram aprofundadas por Tignon et al. (2011), em que a técnica de qPCR foi ampliada para um formato multiplex, que detecta, simultaneamente, a presença de genes da beta-actina de artiodáctilos para controle endógeno de extração de DNA em tecidos. Tal técnica foi aprovada por laboratórios de referência da União Europeia (EU), com métodos de validação bastante rigorosos.

O objetivo deste trabalho foi avaliar e comparar o desempenho das três técnicas de qPCR para diagnóstico de PSA citadas (PSA-OIE, PSA-USDA e PSA-EU).

\section{MATERIAL E MÉTODOS}

PCR quantitativa (qPCR). Os oligonucleotídeos utilizados nas técnicas de qPCR para diagnóstico de PSA estão indicados no Quadro 1. Todas as reações foram realizadas com volume final de $25 \mu \mathrm{L}$ (exceção de beta-actina com $10 \mu \mathrm{L}$ ) no termociclador LC480 (Roche, Alemanha) nas seguintes condições: $50^{\circ} \mathrm{C}$ por 2 $\min , 95^{\circ} \mathrm{C}$ por $15 \mathrm{~min}, 45$ ciclos de $95^{\circ} \mathrm{C}$ por $15 \mathrm{~s}, 60^{\circ} \mathrm{C}$ por $60 \mathrm{~s}$. Na reação PSA-USDA houve adição de $\mathrm{MgCl}_{2}$ para concentração final de $2 \mathrm{mM}$. Além destes, apresentam-se também os iniciadores das qPCR de beta-actina, para averiguação da eficiência do processo de extração de DNA.

Controles positivos. As sequências-alvo do DNA viral dos produtos esperados das qPCR realizadas foram inseridos em plasmídeos sintéticos (CPS) pCR2.1 (Promega, EUA) para serem utilizados, em diluições seriadas, como controles positivos e determinação do limite de detecção das técnicas. As soluções de estoque de CPS foram preparadas na concentração de 1,0ng/ $\mu \mathrm{L}$, diluídas em água deionizada tratada com dietilpirocarbonato (DPEC). Foram utilizadas amostras de RNA do vírus de Peste Suína Clássica e de DNA do vírus da Doença de Aujeszky e da Parvovirose Suína como controles para provas de especificidade analítica.

Determinação dos limites de detecção. Foram realizadas diluições seriadas do CPS estoque de $1 \times 10^{-2}$ a $1 \times 10^{-6}$ e aplicadas nas reações de qPCR em triplicata. Foi determinado como limite de detecção de cada técnica a quantidade de DNA equivalente à última diluição de CPS detectada.

Amostras biológicas de referência. Foi utilizado um painel 
de 14 amostras de referência de tecidos liofilizados, incluindo casos experimentais e clínicos e coletadas de diferentes situações epidemiológicas, sendo uma fraco-positiva, sete positivas e seis forte-positivas. As amostras foram gentilmente cedidas ao Ministério da Agricultura, Pecuária e Abastecimento (MAPA) do Brasil pelo Laboratório de Referência da União Europeia para a Peste Suína Africana - EURL-ASF (Centro de Investigação em Sanidade Animal - CISA, Instituto Nacional de Investigação e Tecnologia Agrária e Alimentar - INIA, Ministério de Ciência e Inovação da Espanha). As amostras foram inativadas por aquecimento a $56^{\circ} \mathrm{C}$ por 70 minutos e seguidas por liofilização pelo CISA-INIA antes de serem disponibilizadas. Antes da extração de ácidos nucleicos das amostras, as mesmas foram ressuspendidas em $1 \mathrm{~mL}$ de água deionizada tratada com DEPC.

Extração de DNA. Para extração do DNA total de tecidos foi utilizado o kit comercial QIAamp Cador Pathogen Minikit $250^{\circledR}$ (Qiagen, EUA). 0 volume final de solução de DNA extraído foi de $100 \mu \mathrm{L}$, conforme recomendações do fabricante. Para verificar a eficiência da extração do DNA a partir de tecidos, as amostras foram submetidas à qPCR para detecção do gene normalizador celular da beta-actina, conforme descrição de Bielanski et al. (2009).

Verificação de desempenho. Para cada qPCR deste experimento, vinte e uma amostras de tecidos suínos saudáveis (aproximadamente $50 \mathrm{mg}$ ) foram contaminados com $10 \mu \mathrm{L}$ de solução de CPS, sendo três amostras de CPS com diluição de $1 \times 10^{-2}$ (100pg de DNA) e quatro com diluições de $1 \times 10^{-3}$ (10pg de DNA). Sete amostras de tecido não contaminados foram utilizadas para extração de DNA para inclusão em paralelo na mesma etapa de verificação de desempenho dos ensaios com as amostras positivas. A avaliação da repetitividade foi feita com a repetição dos ensaios durante três dias seguidos, executados por dois analistas diferentes, desde a etapa de extração de DNA a partir das amostras de tecidos contaminadas com CPS, utilizando-se os mesmos reagentes e equipamentos conforme descrito por Fonseca Jr et al. (2013). Para avaliação da reprodutibilidade intralaboratorial das técnicas, as reações foram aplicadas com as amostras obtidas por apenas um analista, utilizando equipamento diferente e o mesmo mix comercial (robustez de equipamento) e, outrora, utilizando o mesmo aparelho com mix de reagentes diferentes (robustez de reagentes).

Especificidade diagnóstica. Realizaram-se as três qPCR com o DNA de 300 amostras de tecidos de suínos para verificar a ocorrência de reações cruzadas com o genoma da espécie Sus scrofa.

Especificidade analítica. Realizaram-se as três qPCR com controles positivos padronizado para diagnóstico de cada uma das doenças de suínos: Peste Suína Clássica, Parvovirose e doença de Aujeszky.

Sensibilidade diagnóstica. Realizaram-se as três qPCR contra painel de referência.

Reprodutibilidade interlaboratorial. Trinta amostras de tecidos suínos foram preparadas conforme a verificação de desem- penho sendo oito amostras não contaminadas, oito contaminadas com CPS diluído $1 \times 10^{-2}$ (100pg de DNA), onze com $1 \times 10^{-3}$ (10pg de DNA) e três com $1 \times 10^{-4}$ (1pg de DNA). As amostras foram encaminhadas para o Laboratório de Retroviroses da Escola de Veterinária da UFMG sem discriminação entre amostras positivas e negativas. Todo o processo metodológico de extração de DNA e qPCR descrito foi realizado, fazendo-se uso dos mesmos reagentes para extração e qPCR. 0 equipamento utilizado de qPCR foi Real Time PCR 7500 (Applied Biosystems, EUA).

Análise estatística. Os valores de ciclo limiar (Ct) obtidos na Verificação de Desempenho foram avaliados em triplicata para cada ensaio considerando as variações de dias, analistas, equipamentos e reagentes para Análise de Variância (ANOVA), em que a determinação das variâncias dos erros das medidas em repetitividade e reprodutibilidade foram utilizadas para a verificação da aceitabilidade do sistema de medidas de acordo com o Manual de verificação de desempenho de métodos para diagnóstico molecular de doenças infecciosas na rede nacional de laboratórios agropecuários do Ministério da Agricultura (Fonseca Jr et al. 2015).

\section{RESULTADOS}

Padronização das técnicas de qPCR e Limite de detecção

Seguindo os protocolos dos autores das três qPCR, as técnicas foram padronizadas após serem realizadas com diferentes mix de reagentes e com variação nas concentrações de iniciadores e sondas. Foram consolidados os protocolos, com reagentes e concentrações, em cujos resultados foram obtidas melhores sensibilidade e repetibilidade. Não houve alteração nas concentrações de iniciadores e sondas utilizadas por seus autores. Melhores desempenhos da técnica de PSA-USDA foram conseguidos com a adição de mais $\mathrm{MgCl}_{2}$ ao mix total das reações.

Determinou-se a diluição de $1 \times 10^{-5}$ como o limite de detecção das técnicas, conforme os resultados encontrados frente a diferentes diluições seriadas do controle positivo. Os valores de Ct médios obtidos a partir das diluições seriadas do plasmídeo controle positivo estão apresentadas no Quadro 2, para as três reações de qPCR.

\section{Verificação de desempenho}

A análise de variância (ANOVA) realizada na verificação de desempenho está apresentada no Quadro 3, onde se verificam os valores de variância das fontes de avaliação de repetitividade e reprodutibilidade para a comparação entre os testes de qPCR, considerando as variações entre analistas, entre equipamentos e entre mix de reagentes, e a repetição dos ensaios durante três dias consecutivos.

Quadro 1. Oligonucleotídeos iniciadores utilizados nas qPCR

\begin{tabular}{|c|c|c|c|c|c|}
\hline qPCR & & Sequência & Concentração $(\mu \mathrm{M})$ & Máster Mix & Referência \\
\hline \multirow[t]{3}{*}{ PSA-OIE } & reverse & GATACCACAAGATCRGCCGT & 2,0 & RealQ-PCR Master & King et al. (2003); \\
\hline & forward & CTGCTCATGGTATCAATCTTATCGA & 2,0 & Mix Kit - Ampliqon ${ }^{\circledR}$ & \\
\hline & sonda & (FAM)CCACGGGAGGAATACCAACCCAGTG(IowaBlack) & 0,4 & & \\
\hline \multirow{2}{*}{ PSA-USDA } & forward & CCTCGGCGAGCGCTTTATCAC & 0,3 & Mix TaqMan - Qiagen ${ }^{\circledR}$ & \\
\hline & sonda & (FAM)CGATGCAAGCTTTAT(MGB/NFQ) & 0,2 & & \\
\hline PSA-EU & reverse & CCACTGGGTTGGTATTCCTC & 0,24 & & Tignon et al. (2011) \\
\hline \multirow[t]{3}{*}{ Beta-actina } & reverse & TGCCGGAGCCGTTGT & 0,5 & & BielanskI et al. (2009) \\
\hline & forward & AACAGTTTCGCCATGGAT & 0,5 & & \\
\hline & sonda & (Cy5)TGATATTGCTGCGCTCGTGGTC(IowaBlack) & 0,5 & & \\
\hline
\end{tabular}




\section{Especificidades diagnóstica e analítica}

Não houve reações de qPCR para PSA positivas com emprego de DNA de tecidos suínos não contaminados, nem com controles positivos contendo RNA de vírus de Peste Suína Africana ou DNA de vírus da Parvovirose Suína e da Doença de Aujeszky.

\section{Sensibilidade diagnóstica}

Os resultados de Ct dos testes de qPCR com amostras positivas para PSA estão detalhados no Quadro 4, bem como a classificação diagnóstica feita pelo CISA-INIA e a categoria genotípica do vírus envolvido na infecção/contaminação.

\section{Reprodutibilidade interlaboratorial}

Os resultados obtidos pelas três qPCR a partir das amostras preparadas para o teste interlaboratorial estão demonstrados no Quadro 5, com valores de Cts para cada.

\section{DISCUSSÃO}

As técnicas de PCR trazem muitas vantagens para o diagnóstico de doenças, seja em surtos ou levantamentos epi-

Quadro 2. Valores médios de Ct (Ctm) e desvio padrão (DP) obtidos nas qPCR para PSA e curva de diluição do controle positivo plasmidial

\begin{tabular}{|c|c|c|c|c|c|c|c|}
\hline \multirow[b]{2}{*}{$\begin{array}{l}\text { Diluição } \\
\text { do CPS }\end{array}$} & \multirow[b]{2}{*}{$\begin{array}{c}\text { Massa de } \\
\text { DNA }\end{array}$} & \multicolumn{2}{|c|}{ PSA-OIE } & \multicolumn{2}{|c|}{ PSA-USDA } & \multicolumn{2}{|c|}{ PSA-EU } \\
\hline & & $\mathrm{CTm}$ & DP & CTm & DP & CTm & DP \\
\hline $1 \times 10-6$ & $0,01 \mathrm{pg}$ & $>45$ & - & $>45$ & - & $>45$ & - \\
\hline $1 \mathrm{x}$ & $1 \mathrm{pg}$ & 39,45 & 0,43 & 38,74 & 0,26 & 41,03 & 0,39 \\
\hline $1 \times 10-4$ & $1 \mathrm{pg}$ & 35,92 & 0,22 & 34,98 & 0,66 & 36,64 & 0,19 \\
\hline $1 \times 10-3$ & $10 \mathrm{pg}$ & 32,31 & 0,11 & 31,43 & 0,34 & 32,43 & 0,28 \\
\hline $1 \times 10-2$ & $100 \mathrm{pg}$ & 28,77 & 0,21 & 27,66 & 0,14 & 28,41 & 0,46 \\
\hline
\end{tabular}

Quadro 3. Valores de Análise de variância (ANOVA) dos erros de análise das medidas entre analistas (repetitividade) e entre mix de reagentes e equipamentos (reprodutibilidade)

\begin{tabular}{lccc}
\hline Variância do erro da análise & PSA-OIE & PSA-USDA & PSA-EU \\
\hline Analistas - Repetitividade & 0,67 & 1,32 & 1,75 \\
Mix de reagentes - Reprodutibilidade & 0,31 & 0,25 & 1,96 \\
Equipamentos - Reprodutibilidade & 1,02 & 0,24 & 1,73
\end{tabular}

Quadro 4. Valores de Ct obtidos nas três qPCR para PSA com amostras de referência de tecidos

\begin{tabular}{cccccc}
\hline $\begin{array}{c}\text { № da } \\
\text { amostra }\end{array}$ & Classificação & $\begin{array}{c}\text { Genótipo } \\
\text { de VP72 }\end{array}$ & PSA-OIE & PSA-USDA & PSA-EU \\
\hline 1 & Positivo & II & - & 39,00 & 42,54 \\
2 & Fraco Positivo & X & - & 42,63 & 42,47 \\
3 & Positivo & I & 32,93 & 29,30 & 31,60 \\
4 & Forte Positivo & IX & 30,51 & 27,51 & 29,60 \\
5 & Forte Positivo & X & 32,27 & 29,85 & 31,21 \\
6 & Forte Positivo & I & 32,26 & 29,37 & 31,13 \\
7 & Positivo & I & 33,25 & 30,96 & 32,25 \\
8 & Forte Positivo & I & 32,38 & 29,19 & 30,95 \\
9 & Positivo & IX & 32,01 & 28,84 & 30,83 \\
10 & Forte Positivo & IX & 30,50 & 27,32 & 29,23 \\
11 & Forte Positivo & II & 30,06 & 27,06 & 29,49 \\
12 & Positivo & I & - & 36,15 & 39,15 \\
13 & Positivo & I & - & 39,32 & 42,18 \\
14 & Positivo & X & 33,78 & 27,57 & 31,58
\end{tabular}

Quadro 5. Valores de Ct obtidos nas três qPCR para PSA em teste interlaboratorial com amostras contaminadas com CPS

\begin{tabular}{lccc}
\hline Amostra & PSA-OIE & PSA-USDA & PSA-EU \\
\hline Negativas & - & 44,28 & - \\
& - & - & - \\
& - & - & - \\
& - & - & - \\
Cps 1 x 10-2 100 pg de DNA & - & - & - \\
& - & - & - \\
& - & - & - \\
& - & - & - \\
& 26,30 & 27,72 & 27,15 \\
& 27,38 & 27,78 & 27,93 \\
& 27,54 & 28,41 & 28,42 \\
& 27,31 & 28,05 & 27,86 \\
& 26,47 & 27,48 & 27,34 \\
& 26,95 & 28,10 & 27,88 \\
& 26,27 & 27,40 & 27,25 \\
Cps 1 x 10-4 1 pg de DNA 10 pg de DNA & 26,59 & 27,50 & 27,57 \\
& 32,96 & 32,61 & 32,81 \\
& 32,41 & 33,38 & 32,18 \\
& 28,65 & 28,70 & 28,40 \\
& 32,19 & 32,56 & 32,30 \\
& 31,58 & 32,18 & 31,91 \\
& 30,95 & 31,79 & 31,57 \\
& 28,64 & 29,21 & 29,29 \\
& 30,37 & 31,27 & 31,13 \\
& 31,99 & 32,22 & 31,70 \\
& 31,63 & 32,17 & 31,84 \\
& 34,94 & 32,70 & 32,81 \\
& 35,40 & 35,72 & - \\
& 34,67 & 34,79 & 35,11 \\
& & & 34,58
\end{tabular}

demiológicos. No caso da investigação a partir de tecidos, são importantes alternativas ao isolamento viral por vários motivos, entre eles a menor manipulação de amostras contaminadas e a possibilidade de detecção mesmo em tecidos degradados. Por outro lado, permitem ainda o reconhecimento de diferentes tipos de genótipos virais, desde que haja variabilidade de técnicas. No caso do vírus da Peste Suína Africana, 22 genótipos já foram identificados (Bastos et al. 2003). A OIE recomenda ainda outras duas técnicas de PCR, sendo uma convencional (Agüero et al. 2003) e outra quantitativa (Fernandez-Pinero et al. 2010).

As padronizações e validações das três técnicas de qPCR comparadas, neste trabalho, tiveram várias semelhanças. Todas adotaram como alvo para as reações o gene p72, aquele que apresenta maiores nível de sequências conservadas e diversidade de genótipos virais, se comparado com outros genes também preconizados em técnicas moleculares (Tignon et al. 2011). A determinação de iniciadores foi obtida pelo alinhamento de várias sequências depositadas no GenBank, oriundas de vírus de até 11 genótipos diferentes. As técnicas utilizaram, ainda, a construção de plasmídeos contendo sequências miméticas do gene p72, justificando que a ausência de outras sequências do genoma viral representaria ganho na especificidade das qPCR. Tignon et al. (2011) e Zsak et al. (2005) fizeram validações mais rigorosas de seus ensaios ao incluir avaliações clínicas após a infecção experimental de suínos com amostras virais crescidas em culturas de células.

A padronização dos três métodos por um mesmo laboratório e a disponibilização em sua rotina amplia a com- 
petência e a credibilidade do diagnóstico, em virtude da ampla variabilidade viral. Erradicada no Brasil na década de 1980, a PSA é uma doença exótica para este mercado e, portanto, é de interesse sanitário e comercial para a suinocultura brasileira que haja diagnósticos oficiais.

Neste trabalho, partiu-se da experiência das três qPCR mencionadas para a aquisição dos iniciadores e sondas de hidrólise TaqMan ${ }^{\circledR}$. A utilização de plasmídeos com as sequências de interesse do gene p72 possibilitou a praticidade das técnicas, o controle da concentração de DNA empregada e a contaminação experimental de amostras de tecidos sem, contudo, interferir no processo de extração de DNA adotado. A partir da técnica para PSA-EU de Tignon et al. (2011), no entanto, não foi desenvolvida a multiplex, com detecção simultânea do gene da beta-actina, um importante normalizador celular. Em vez disso, as reações qPCR para beta-actina foram realizadas em paralelo.

Mantidas as concentrações de iniciadores e sondas preconizadas em seus trabalhos originais, os métodos de PSA-USDA e PSA-EU apresentam-se como importantes alternativas ao método de King et al. (2003), mencionado no manual da OIE, no que se refere a consumo de iniciadores (7,5 e 6,0pmol/reação, respectivamente, frente aos 50 pmol/reação de PSA-OIE). Neste trabalho, no entanto, houve a adição de $\mathrm{MgCl}_{2}$ às reações da qPCR PSA-USDA, no que observou-se melhor desempenho para a padronização da técnica.

Estudos mostram que a sensibilidade de técnicas de qPCR pode ser alterada quando da utilização de diferentes mix de reagentes ou equipamentos, razão pela qual é necessário otimizar a técnica em função destas variações e adotar procedimentos avaliativos seguros para a validação dos ensaios. A composição dos mix de reagentes pode sofrer alterações na composição de tampões ou concentração de cátions, sobretudo $\mathrm{Mg}^{+2}$. Também a presença de inibidores presentes nas amostras tem influencia de maneira diferente sobre cada mix (Stephens et al. 2010). A alternação de uso de equipamentos, de maneira semelhante, pode trazer oscilações nos resultados de Ct obtidos, sobretudo quando não houver padronização de calibração dos aparelhos (Sivaganensan et al. 2012). Buzard et al. (2012) sinalizaram que há limitações em estudos comparativos de técnicas com alternância de equipamentos e reagentes, uma vez que nem sempre é possível seguir todas as recomendações de ambos os fabricantes. Por este motivo, técnicas de qPCR, para fins diagnósticos, precisam ser avaliadas sob métodos estatísticos em que se observem tanto a repetitividade quanto a reprodutibilidade, isto é, a correspondência dos resultados de uma mesma amostra em diferentes rodadas (Albano \& Raya-Rodriguez, 2009).

Na análise de variância dos dados de verificação de desempenho não foram encontradas diferenças significativas entre dias, analistas, equipamentos e mix de reagentes. Considerando diferentes analistas entre as três técnicas, PSA-OIE foi a menos variável. PSA-EU é a mais variável quando é modificado o mix de reagentes ou realizada em outro equipamento, e ainda, ante dois analistas diferentes. Entretanto, estas fontes de variância não causaram erro de análise maior que $5 \%$, configurando a aceitabilidade ou adequação do sistema de medidas adotado. Este resultado é uma vantagem quando da necessidade prática de se decidir entre diferentes opções de equipamentos ou reagentes para a realização de diagnósticos.

As três técnicas de qPCR apresentaram alta especificidade analítica e diagnóstica, sem reações cruzadas ou inespecíficas com DNA suíno ou de outros agentes virais. Em termos de sensibilidade, das três qPCR, PSA-OIE foi a que apresentou valores de Ct mais altos, comparáveis aos obtidos em PSA-USDA e PSA-EU, e ainda, não houve detecção de amplificação em três amostras consideradas positivas no painel de referência. As amostras de referência cedidas pelo CISA-INIA eram variadas, compreendendo genótipos diferentes da VP72 obtidas tanto de animais inoculados experimentalmente quanto de surtos. Dentre todas as amostras classificadas como positivas e forte-positivas, a qPCR PSA-USDA apresentou melhor desempenho de sensibilidade, com os menores valores de Ct, ante as outras duas técnicas.

A avaliação interlaboratorial feita com amostras contaminadas com plasmídeo representou bem o desempenho das três técnicas em detectar sequências do DNA da VP72 viral. Todos as amostras não contaminadas foram consideradas negativas, entendendo-se como irrelevante o valor de 44,28 de Ct em uma das qPCR PSA-USDA. Apenas uma amostra contaminada com a concentração mais diluída de plasmídeo, mas dentro do limite de detecção, não apresentou amplificação. Os demais resultados obtidos foram considerados satisfatórios, muito próximos entre si, comparando-se as três técnicas. Isso pode ser explicado pelo fato de as amostras de tecido terem sido contaminas pelo mesmo plasmídeo, que contem insertos específicos para os três pares de iniciadores.

\section{CONCLUSÕES}

Os resultados das técnicas de qPCR são promissores e a metodologia aplicada para a validação foi bem sucedida, de maneira que as três podem ser implantadas num mesmo laboratório com capacidade e competência para emitir diagnósticos oficiais a partir de PCR quantitativa.

As técnicas são intercambiáveis e a implantação de mais de uma delas permitirá maior segurança nos resultados no diagnóstico de uma enfermidade de alto impacto na suinocultura.

Agradecimentos.- Os autores agradecem ao Laboratório Nacional Agropecuário (Lanagro-MG), INCT Pecuária and CNPq (Conselho Nacional de Desenvolvimento Cientifico e Tecnológico) Projeto SAGRES: 457417/2012-9.

\section{REFERÊNCIAS}

Agüero M., Fernández J., Romero L., Sanchez C., Arias M. \& Sánchez-Vizcaíno J.M. 2003. Highly sensitive PCR assay for the routine diagnosis of African swine fever virus in clinical samples. J. Clin. Microbiol. 41(9):44314434.

Albano F.M. \& Raya-Rodriguez M.T. 2009. Validação e garantia da qualidade de ensaios laboratoriais. Rede Metrológica, Porto Alegre, RS.

Bastos A.D.S., Penrith M.L., Cruciere C., Edrich J.L., Hutchings G., Roger F., Couacy-Hymann E. \& Thomson G.R. 2003. Genotyping field strains of African swine fever virus by partial P72 gene characterization. Arch, Virol. 148(4):693-706. 
Bielanski A., Algire J., Lalonde A. \& Nadin-Davis S. 2009. Transmission of bovine viral diarrhea virus (BVDV) via in vitro-fertilized embryos to recipients, but not to their offspring. Theriogenology, 71(3):499-508.

Buzard G.S., Baker D., Wolcott M.J., Norwood D.A. \& Dauphin L.A. 2012. Multi-platform comparison of ten commercial master mixes for probebased real-time polymerase chain reaction detection of bioterrorism threat agents for surge preparedness. Forensic Sci. Intl. 223:292-297.

Dixon L.K., Costa J.V., Escribano J.M., Rock D.L., Vinuela E. \& Wilkinson P.J. 2000. Virus taxonomy: classification and nomenclature of viruses, 159165. In: Van Regenmortel M.H.V., Fauquet C.M., Bishop D.H.L., Carstens E., Estes M.K., Lemon S., Maniloff J., Mayo M.A., McGeoch D.J., Pringle C.R. \& Wickner R. (Eds), Seventh Report of the International Committee on Taxonomy of Viruses. Academic Press, London.

De León P., Bustos M.J. \& Carrascosa A.L. 2013. Laboratory methods to study African swine fever vírus. Virus Res. 173:168-179.

Done S., Gresham A., Potter R. \& Chennells D. 2001. PMWS and PDNS/two recently recognised diseases of pigs in the UK. In Practice 21:14-21.

Fernandez-Pinero J., Gallardo C., Elizalde M., Rasmussen T.B., Stahl K., Loeffen W., Blome S., Batten C., Crooke H., Le Potier M.F., Uttenthal Å., Leblanc N., Albina E., Kowalczyk A., Markowska-Daniel I., Tignon M., De Mia G., Giammarioli M., Arias M. \& Hoffmann B. 2010. Epizone ring trial on ASFV real-time PCR. Annual Meeting of National African Swine Fever Laboratories, 18 May 2010, Pulawy, Poland.

Fonseca Jr A.A., Cottorello A.C., D’Ambros R., Leite R.C., Heinemann M.B. \& Reis J.K.P. 2013. PCR em tempo real para detecção do vírus da doença de Aujeszky. Arq. Bras. Med. Vet. Zootec. 65:801-808.

Fonseca Jr A.A., Gouvea M.V., Zaroni M.M.H., Carvalho L.B. \& Xavier S.M. 2015. Manual de Verificação de Desempenho de Métodos para Diagnóstico Molecular de Doenças Infecciosas na Rede Nacional de Laboratórios Agropecuários. MAPA/ACS, Brasília. 57p.

Gallardo C., Fernandez-Pinero J., Pelayo V., Gazaev I., Markowska-Daniel I., Pridotkas G., Nieto R., Fernandez-Pacheco P., Bokhan S., Nevolko O., Drozhzhe Z., Pérez C., Soler A., Kolvasov D. \& Arias M. 2014. Genetic variation among African swine fever genotype II viruses Eastern and Central Europe. Emerg. Infect. Dis. 20(9):1544-1547.

King D.P., Reid S.M., Hutchings G.H., Grierson S.S., Wilkinson P.J., Dixon L.K., Bastos A.D.S. \& Drew T.W. 2003. Development of a TaqMan PCR assay with internal amplification control for the detection of African swine fever virus. J. Virol. Methods 107:53-61.

Moura J.A., McManus C.M., Bernal F.E.M. \& De Melo C.B. 2010. An analysis of the1978 outbreak of African swine fever in Brazil and its eradication. Scientific and Technical Review of the Office International des Epizooties 29(3):549-563.

OIE 2012. Manual of Diagnostic Tests and Vaccines for Terrestrial Animals. Disponível em < http://www.oie.int/en/international-standard-setting/terrestrial-manual/access-online/> Acesso em 15 out. 2015.

Penrith M., Vosloo W., Jori F. \& Bastos A.D.S. 2013. African swine fever virus eradication in Africa. Virus Res. 173:228-246.

Radostits O.M., Gay C.C., Hinchcliff K.W. \& Constable P.D. 2007. Veterinary Medicine: a textbook of the diseases od cattle, horses, sheep, pigs and goats. 10th ed. W.B. Saunders, London. 2065p.

Sivaganensan M., Varma M. \& Haugland R. 2012. Comparison of Enterococcus quantitative Polymerase Chain Reaction analysis results from fresh and marine Waters on two real-time instruments. Analyt. Biochem. 430(1):68-74.

Stephens K.W., Hutchins R.J. \& Dauphin L.A. 2010. Cross-platform evaluation of commercial real-time reverse transcription PCR master mix kits using a quantitative 5'nuclease assay for Ebola virus. Mol. Cell Probes 24:370-375.

Tignon M., Gallardo C., Iscaro C, Hutet E., Van der Stede Y., Kolbasov D., De Mia G.M., Le Potier M., Bishop R.P., Arias M. \& Koenen F. 2011. Development and inter-laboratory validation study of an improved new real-time PCR assay with internal control for detection and laboratory diagnosis of African swine fever virus. J. Virol. Methods 178:161-170.

Tokarnia C.H., Peixoto P.V., Döbereiner J., Barros S.S. \& Riet-Correa F. 2004. 0 surto de peste suína africana ocorrido em 1978 no município de Paracambi, Rio de Janeiro. Pesq. Vet. Bras. 24(4):223-238.

Wilkinson P.J. 1989. African swine fever virus, p.17-37. In: Pensaert M.B. (Ed.), Virus Infections of Porcines. Elsevier Sciences Publishers B.V., Amsterdam.

Zsak L., Borca M.V., Risatti G.R., Zsak A., French R.A., Lu Z., Kutish G.F., Neilan J.G., Callahan J.D., Nelson W.M. \& Rock D.L. 2005. Preclinical diagnosis of African swine fever in contact-exposed swine by a Real-Time PCR assay. J. Clin. Microbiol. 43(1):112-119. 